ALPHA No 26 / Julio 2008 (47-68)

ISSN 0716-4254

http://alpha.ulagos.cl

\title{
ALGUNAS REACCIONES DE LOS PRIMEROS LECTORES DEL LIBRO DE LA VIDA DE TERESA DE ÁVILA SEGÚN EL AUTÓGRAFO ${ }^{1}$ \\ Some readers reactions to the Book of her life by Teresa of Avila according to the autograph
}

Raquel Trillia*

Resumen

Examen de las pocas tachaduras, cambios y adiciones del autógrafo del Libro de la vida de Teresa de Ávila que se encuentra en la Biblioteca del Real Monasterio de El Escorial. Se mostrará que los aspectos de la escritura teresiana que inquietaron a sus primeros lectores (confesores y letrados) eran los que atañían a asuntos doctrinales, en particular, a aquéllos que asemejaban su modo de oración al de los alumbrados, y aquéllos que le daban autoridad al texto, esto último problemático por ser Teresa una mujer. Además, el cuidado con que fue tratado el Libro por la Inquisición delata que fue un trabajo de colaboración entre Teresa y los letrados y confesores que le aconsejaron y con quienes frecuentemente dialogó sobre materias espirituales. El autógrafo es, entonces, la versión ‘final’ del Libro.

Palabras clave: Literatura española, Teresa de Ávila, autógrafo

Abstract

This paper examines the few additions, deletions and corrections of the autograph of the Book of Her Life (Libro de la vida) of Teresa de Avila found in the Biblioteca del Real Monasterio of El Escorial. This study reveals that the aspects of teresian writing that troubled her early readers fell into two categories: those that presented doctrinal problems and those that gave the textual voice authority, the latter problematic because Teresa was a woman. However, the care that inquisitorial readers took to make these corrections suggests that the Book was a work of collaboration between Teresa and the confessors and learned men who advised her, and with whom she frequently discussed spiritual matters. Therefore, the autograph may be considered the 'final' version of the Book.

Key Words: Spanish literature, Teresa of Ávila, autograph

\footnotetext{
${ }^{1}$ Este trabajo ha sido posible gracias a la edición paleográfica del Libro de la Vida de Tomás Álvarez (1999) y a una beca de la Universidad de Lethbridge que me permitió consultarla. Todas las citas del Libro han sido tomadas de esta edición.
} 


\section{Raquel Trillia}

El Libro de la vida escrito por Teresa de Ávila entre los años 1562 y 1565, pretendía, entre otras cosas, justificar su modo de oración. A partir de 1565 se hacen varias copias del texto que circulan ${ }^{2}$ causando alarma en algunos círculos religiosos. Cuando en 1575 se acusa a Teresa en Córdoba, Valladolid y Sevilla frente a la Inquisición, ésta ordena intervenir el Libro, dándoselo al P. Domingo Báñez para que lo examinara. A pesar del juicio favorable de Bañez, el Libro queda en manos de la Inquisición hasta $1586^{3}$ y Teresa nunca supo cuál fue el veredicto oficial del Santo Oficio (Ahlgren, 1996: 64) ya que murió en $1582 .{ }^{4}$

La historia del manuscrito frente a la Inquisición ${ }^{5}$ señala la desconfianza que causaban las experiencias espirituales sobrenaturales y cualquier desviación heterodoxa, y subraya el precario clima religioso del siglo XVI en el que le tocó escribir a Teresa. Debió cuidar la manera en que se expresaba (ya como persona religiosa, ya como mujer) y deseaba/necesitaba que se confirmase la ortodoxia de su trayectoria espiritual, ya que su texto "no se escribió desde el seno de la autoridad eclesiástica” (Fernández 285). Por esto, quería que figuras como el Maestro Ávila leyeran el texto. En el epílogo del Libro, la carta que le dirige al padre García de Toledo que acompaña el manuscrito, Teresa escribe: "Suplico a vuestra merced lo enmiende y mande trasladar, si se ha de llevar al P. Maestro Ávila, porque podría ser conocer alguien la letra. Yo deseo harto se dé orden en cómo lo vea...” (Epílogo 2). Teresa convierte el mandato original que recibió de sus confesores para que escribiera su "modo de oración y mercedes" (Prólogo 1) — para ser

\footnotetext{
2 Álvarez resume la circulación del Libro de la siguiente manera: "Fueron tres los cauces de difusión por los que fluyó el escrito de Teresa: el grupo de letrados dominicos de Ávila; el obispo diocesano don Álvaro y su hermana doña María de Mendoza; y, en tercer lugar, el Maestro Ávila y sus discípulos de Andalucía” (1996b: 520). Según Weber, fueron cuatro los grupos de personas que leyeron el Libro en forma manuscrita: el clero, monjas Carmelitas Dezcalzas y algunas monjas de otras órdenes, mecenas laicos, y mujeres de la alta nobleza y miembros de la familia real (2003: 112).

${ }^{3}$ Mediante su influencia, Ana de Jesús logró recuperar los manuscritos de Teresa en 1586, cuando las Carmelitas preparaban una edición de la obra de Teresa (Ahlgren, 1996: 64, n.112).

${ }^{4}$ Extraoficialmente, sí, tuvo alguna noticia de la respuesta de la Inquisición a su Libro. En una carta a su hermano Lorenzo le cuenta que, por intermedio de doña Luisa de la Cerda, sabe que los inquisidores no han encontrado nada que censurar, "antes había bien que mal” (180.14). Todas las citas de la obra teresiana que no pertenecen al Libro están tomadas de la edición de Llamas, Egido et al.

${ }^{5}$ Álvarez documenta detalladamente en su Nota histórica la vida y tribulaciones del Libro de la vida desde sus antecedentes y primera redacción en casa de la dama Doña Luisa de la Cerda en 1562, hasta su publicación por Fray Luis de León en 1588, incluyendo la intervención del tribunal de la Inquisición (503-555). Alison Weber, en “The Three Lives of the Vida” también trata la historia del texto del Libro.
} 


\section{Algunas reacciones de los primeros lectores del Libro de la Vida}

examinado - en un pedido que les hace de que se leyera, revisara y censurase su texto para confirmar la ortodoxia del mismo. ${ }^{6}$

Dado el deseo/necesidad de Teresa de que se asegurase la ortodoxia de su oración, el Libro es leído por varios confesores y letrados. ${ }^{7}$ Algunos de estos lectores (contemporáneos de Teresa) dejaron testimonio de su lectura del Libro en informes, cartas y prólogos. ${ }^{8}$ Otros, mediante marcas anónimas en el autógrafo. ${ }^{9}$ Las lecturas del manuscrito que se tratarán aquí son las que atestiguan estas marcas anónimas que han sido documentadas, total o parcialmente, por los varios editores del Libro de la vida. Sin detenernos en

${ }^{6}$ El título que el P. Gracián le da al Libro en el manuscrito de las Carmelitas Descalzas de Salamanca incluye que Teresa "escribiolo para dar cuenta a su confesor de las cosas extraordinarias de su alma para que se examinasen si eran de Dios”. Cfr. Álvarez, 1995: xxv.

${ }^{7}$ Según Weber, además de ser leído por confesores, el Libro es leído (total o parcialmente) por monjas, mujeres de la alta nobleza y mecenas (112). De algunos de sus lectores tenemos noticias precisas — como de aquéllos a quienes iba dirigido el Libro - entre ellos, su confesor García de Toledo; Gaspar Daza, clérigo licenciado y Francisco de Salcedo, caballero que practicaba oración mental (Libro 23.14). De otros lectores tenemos noticia por su relación con el autógrafo, como doña Luisa de la Cerda, quien tenía encomendado enviarlo al Maestro Ávila (Cartas 7 y 8 del epistolario teresiano). O, como el obispo de Ávila, don Álvaro de Mendoza, a quien Teresa había enviado el autógrafo. Mendoza mandó hacer una copia para su hermana, doña María (Llamas Martínez, 1972:250). En otros casos, Teresa señala algún lector. En el prólogo de El Libro de las Fundaciones señala que el padre Jerónimo Ripalda había leído el Libro y le pareció sería servicio de nuestro Señor que escribiese de otros siete monasterios que, después acá, [...] se han fundado” (Prólogo 2). El testimonio de Domingo Báñez en los procesos de beatificación y canonización de Teresa confirma que circularon varias copias del texto ("Proceso" 1:10).

${ }^{8}$ Por ejemplo, la “Censura del P. Domingo Báñez en el autógrafo de la Vida,” escrito a pedido del inquisidor don Francisco de Soto y Salazar en 1575 (Llamas Martínez, 1972:261). Báñez confirma la ortodoxia de la oración de Teresa, aunque concede que no debe circular antes de la muerte de ella. Otros ejemplos son la carta (fechada en 1568) que le envía a Teresa el Maestro Ávila una vez leído el autógrafo (De la Fuente,1877, II:504; Álvarez 1995:628-630), el prólogo de Fray Luis de León a la primera edición de las Obras de Teresa y la carta de Alonso de la Fuente (26 de agosto, 1589) dirigida al Tribunal de la Inquisición que abrió el proceso contra la obra impresa de Teresa el mismo año (Llamas Martínez, 1972:395-6). Según De la Fuente, el libro de Teresa “tiene la ponçoña de la heregía,” por lo cual podía ser peligroso "para gente que duerme, aunque sean los más subidos teólogos” (Llamas Martínez, 1972:396). Estas respuestas escritas al texto teresiano proveen los juicios que emitieron estos lectores particulares en relación al Libro.

${ }^{9}$ Salvo casos contados, estas marcas no impiden la lectura del texto y reflejan que fue leído con cuidado y respeto, al menos, como una cosa física, ya que todavía está en excelente condición de lectura. "Durante los años de prisión el manuscrito no sufrió los acostumbrados cercenes ni malos tratos, ni las acostumbradas tachas y 'expurgatur' de libros coetáneos. [...] En el autógrafo teresiano no quedan huellas ni rasguños de su paso por el tribunal” (Álvarez, Nota 526). Hecho notable si se compara el autógrafo de Teresa con el del Libro del Conorte, por ejemplo, que registra las visiones de la Madre Juana de la Cruz (1481-1534). Este manuscrito tiene páginas enteras tachadas o pintadas, y sus márgenes están muchas veces repletos de notas escritas en letra minúscula (El Escorial MS J-II-18). 


\section{Raquel Trillia}

la identidad de los autores ${ }^{10}$ de estas marcas, podemos estudiar las enmiendas y adiciones del texto con el objetivo de establecer qué elementos del texto los provocaron a modificarlo de alguna manera. Estos lectores corrigieron errores ortográficos u omisiones del texto, tacharon frases, reemplazaron vocablos y marcaron algunas líneas y párrafos. ${ }^{11}$ Un examen cuidadoso de las pocas tachaduras, cambios y adiciones del autógrafo del Libro de la vida de la Biblioteca del Real Monasterio de El Escorial mostrará que los aspectos de la escritura teresiana que inquietaban a estos lectores eran los que atañían a asuntos doctrinales, en particular, aquéllos que asemejaban su modo de oración al de los alumbrados, o aquéllos que le daban autoridad al texto, siendo problemático esto último por ser Teresa una mujer. Además, el cuidado con el que fue tratado el Libro por la Inquisición delata que fue un trabajo de colaboración entre Teresa y los letrados y confesores que le aconsejaron: "Teresa's spiritual autobiography, in the version that we read today, is the culmination of an eleven-year process of writing and rewriting”. ${ }^{12}$ El autógrafo que se encuentra en El Escorial podría, entonces, calificarse como la versión 'final' del Libro, lo cual explica el pequeño número de enmiendas hechas al autógrafo.

\section{EL ALUMBRADISMO}

En el siglo XVI, muchos buscaban perfección espiritual. Este deseo emanó de que se buscara a Dios, en palabras de Julio Caro Baroja, "con una intensidad y ardor que acaso no se han dado ni antes ni después” (45). Este fervor religioso dio lugar a movimientos espirituales —alumbradismo, luteranismo, calvinismo, erasmismo - y a reformas y disidencias dentro de las órdenes religiosas. ${ }^{13}$ Los alumbrados, doctrina que nos interesa particularmente y que se le adjudicó a la beata Isabel de la Cruz y a su

\footnotetext{
${ }^{10}$ En contados casos puede identificarse con certeza la mano que hiciera las marcas en el autógrafo del Libro. Dado que la única persona que firma el manuscrito (además de Teresa) es Báñez, los editores de Teresa le atribuyen muchas de las correcciones.

${ }^{11}$ Este grupo de marcas de otra mano (excluyendo las que corrigen o enmiendan errores ortográficos o gramaticales de la autora, o que retocan su letra) simplemente señalan una línea o pasaje específico en el texto. Estas marcas pueden clasificarse según su forma, ya que algunas líneas del texto se encuentran señaladas en los márgenes por una o dos líneas transversales, uno o más puntos, cruces (no todas iguales) o llaves. Además, algunas líneas se encuentran subrayadas.

12 "La autobiografía espiritual de Teresa, en la versión que leemos hoy, es la culminación de un proceso y escritura y reescritura que duró once años” (Weber, 2003. 108). Esta traducción y las siguientes son mías.

13 Según Andrés, esta diversidad espiritual explica que surgieran "tantas tensiones y confusiones” dada la preocupación de la Iglesia por preservar su ortodoxia (1987:119).
} 
Algunas reacciones de los primeros lectores del Libro de la Vida

discípulo Pedro Ruiz de Alcaraz, eran adeptos al dejamiento. Los dejados procuraban unirse a lo divino "por la iluminación para formar parte de ello, procurando diluirse allí mentalmente, por vía de no afirmación de la libre voluntad, aunque ésta fuese para actos de virtud” (López Santidrián, 1975: 75. Cfr. Manuel Serrano y Sanz, 1903: 10).

El miedo al alumbradismo (y al luteranismo) se concretó en Toledo en 1525, cuando el Inquisidor General Don Alonso Manrique promulgó el Edicto contra los alumbrados. Pero el problema de la ortodoxia se remonta a 1519 cuando Isabel de la Cruz y Alcaraz fueron denunciados ante la Inquisición.

Isabel de la Cruz, terciaria de la Orden Franciscana, para 1512 predicaba en Guadalajara: “Acompañándose con explicaciones de las Escrituras y exégesis, predicó deponer, ante la de Dios, nuestra propia voluntad y, consecuentemente, la sumisión del individuo, en todas las cosas, a la divina dirección” (Longhurst, 1957:280). La denuncia de 1519 no parece haber atraído suficiente atención por parte de los Inquisidores e Isabel pudo seguir con sus actividades misioneras. Pero, para fines de 1523 o principios de 1524 "los inquisidores de Toledo estaban suficientemente persuadidos de que existía una amenaza contra la ortodoxia” (Longhurst, 1957:284).

Pedro Ruiz de Alcaraz, secretario de profesión (Nieto, 1987: 432) e hijo de un panadero converso de Guadalajara (Serrano y Sanz, 1957: 6; Bataillon, 1966:180), pertenecía al grupo de La Salceda, ${ }^{14}$ y como discípulo de Isabel de la Cruz también fue procesado por la Inquisición. Durante el proceso, Pedro de Rueda declaró, con la ayuda de otros vecinos, que Alcaraz "enseñaba el dexamiento" y en 1524 Alcaraz fue encarcelado (Serrano y Sanz, 1903: 9). Fue torturado recién en 1527, y aun entonces el Santo Oficio no pudo dictar una condena. En 1529, Alcaraz pidió clemencia y confesó sus errores; ahora los inquisidores podían sentenciarlo. La sentencia, pronunciada el 22 de julio del mismo año, condenaba a Alcaraz a prisión perpetua, pena que sólo en 1539 fue conmutada: “Alcaraz salió de la cárcel, pero quedó obligado a residir en Toledo, rezar los viernes los siete Salmos penitenciales en el convento de San Agustín; los sábados el rosario; ayunar un día en semana y cumplir otras penitencias" (Serrano y Sanz, 1903: 129). No es sabido cuál fue el final de Isabel, pero dadas las similitudes de su caso con el de Alcaraz, Longhurst especula que su juicio y castigo fueran parecidos a los de Alcaraz (1957:303). ${ }^{15}$

\footnotetext{
${ }^{14}$ Una casa de recolección cuyos moradores se dedicaban a la oración, al estudio y a la penitencia, además de predicar en las villas circundantes (López Santidrián 14).

${ }^{15}$ Otra discípula de Isabel, María de Cazalla, también fue denunciada ante la Inquisición en 1530 y, nuevamente, en 1532. La apresaron en abril de 1532 y en 1534 fue torturada. Recibió, finalmente, una sentencia "moderada" y salió de la cárcel el 20 de diciembre de ese año (Longhurst 281 n.7; Batatillon 1980:471-74). Según Márquez, “[e]n la causa de María de
} 


\section{Raquel Trillia}

Uno de los resultados de estas denuncias fue el Edicto contra los alumbrados, dexados y perfectos promulgado en 1525 por el arzobispado de Toledo. Este documento refleja la alarma causada porque "entre muchas personas se dezian, conferían y publicaban algunas palabras que parescían desviarse de nuestra santa fee católica e la comun observancia de los fieles christianos e de nuestra Sancta Madre Yglesia, e se contaban e facían conventículos particulares secreta e públicamente, e algunos se dezian alumbrados, dexados o perfectos” (Márquez, Apéndice I 1980: 229-30). Y los procesos contra personas como Alcaraz llevaron a la categorización de las ideas llamadas alumbradas. Según Ángela Selke el contenido del Edicto está basado en gran parte en las cartas escritas por Alcaraz y en los testimonios del proceso inquisitorial contra él en 1524 (1952:126; Cfr. Márquez, 36). Antonio Márquez está de acuerdo con la posición que adopta Ángela Selke con respecto al origen de las ‘doctrina' de los alumbrados

El Edicto, leído en todas las iglesias año tras año, era engañoso en más de un respecto. Nadie había defendido, ni individual ni colectivamente, todas las doctrinas contenidas en este original documento. Las proposiciones se limitaban a reproducir pasajes de denuncias concretas sobre personas concretas. [...] El Edicto pasó por una doctrina sistemática y uniforme cuando en realidad no era más que un centón de denuncias, empírica y programáticamente organizadas, para liquidar a elementos peligrosos, más o menos afines, en tal o cual punto, a la revolución religiosa y social que se desarrollaba en Europa (66).

Según Márquez no hubo ningún grupo u organización que se autodesignara alumbrado. La Inquisición, en su deseo de controlar las ideologías heréticas, definió alumbradismo e intentó definir su doctrina. "Los inquisidores trataban, al parecer, de disolver la gran herejía [luterana] en una serie de herejías pequeñas, menos terríficas” (Selke, 127). El Edicto refleja el temor que causaba la pluralidad religiosa.

Otra consecuencia de las denuncias de alumbradismo fue la cuidadosa definición de recogimiento por parte de Francisco de Osuna, quien, como Alcaraz, pertenecía al grupo de La Salceda, aunque no siempre estuvo de acuerdo con él. Sus desacuerdos llevaron a Osuna a escribir sus Abecedarios. El Tercer Abecedario, publicado por primera vez en 1527, defiende el recogimiento, cuyos "esquemas, idos de mano en mano", según Osuna, no habían sido interpretados correctamente (López Santidrián, 65). Necesitaba diferenciarlo del dejamiento, que condenaba como erróneo. En el Prólogo,

Cazalla (1531-1535) parecen darse cita todas las tendencias heterodoxas de la época (iluminismo, erasmismo, luteranismo)” (37). 


\section{Algunas reacciones de los primeros lectores del Libro de la Vida}

Osuna explica que el recogimiento "no es para todos; [...] aquí como en cosa más sutil suelen los no avisados errar con más peligro, y de hecho han errado muchos, no por seguir el recogimiento, sino porque, pensando que lo seguían, se apartaron de él a otras sendillas algo deleitosas...” (87). Vuelve a hacer referencia a los dejados o alumbrados en el Tratado 17: "ahora hay una manera de santidad que, allende de no hacer fruto en la Iglesia ni dar ejemplo en sí, junta el hierro de la fortaleza del espíritu y el barro de la flaqueza humana, [...] y dicen que la relajación y la devoción han de morar juntas, como sean más enemigas en toda buena costumbre, que no el hierro y el barro en el ser de naturaleza para se juntar” (477; $c f$. 561). Queda claro que Osuna quería defender su modo de oración interior y protegerlo de asociaciones con movimientos heterodoxos. Teresa declara haber leído el Tercer Abecedario; es más, su lectura fue decisiva en su vida espiritual (Libro 4.7). Asocia su modo de oración con el de Osuna, ya que para explicarlo usa el término "recogimiento" repetidas veces en el Libro (en particular, Capítulos 13, 14 y 15, 40.6). ${ }^{16}$ También usa la palabra recogimiento para describir sus experiencias místicas (por ejemplo, Libro 31.12, donde iguala recogimiento con arrobamiento). ${ }^{17}$ Más adelante veremos que, a pesar de usar el término recogimiento, sus descripciones ciertamente tienen por lo menos un dejo de alumbradismo.

Las experiencias de Isabel, Alcaraz y María Cazalla, cuyas ideas socavaban la infalibilidad de la autoridad de la Iglesia y el clero (Nieto 1987:444), ilustran las tensiones y las severas consecuencias que desacuerdos y diferencias de naturaleza espiritual y religiosa podían tener en el siglo XVI. Durante todo el siglo los problemas de interioridad y las maneras de expresarlos de los místicos (sin usar del lenguaje escolástico deductivo) produjeron sospechas y disputas hasta entre los miembros de las órdenes religiosas por ser afines a los de los alumbrados, erasmistas o luteranos (Andrés 1987:458), ya que todos estos grupos insistían en una relación más personal e íntima del alma con Dios en la cual no había intermediarios (por ejemplo, sacerdotes, la Iglesia o el intelecto). La misma Teresa hace referencia a los "tiempos recios" que vive, y reconoce "que podría ser me levantasen algo y fuesen a los inquisidores" (Libro 33.5).

\footnotetext{
${ }^{16}$ El término recogimiento lo usa también en Camino de Perfección (Capítulo 28) y en Las Moradas (Morada cuarta, Capítulo 3), en ambos casos para describir su modo de oración. Además, usa la palabra recogimiento en la Relación 3 en la cual explica su actitud espiritual (3.11) y en la Relación 53.4 donde explica los grados de oración.

${ }^{17}$ Cfr. Libro 24.17, 27.3, 31.6, 38.30, 38.31, 40.12.
} 


\section{Raquel Trillia}

\section{EL PROBLEMA DE LA MUJER EN EL SIGLO XVI}

Además de tener conciencia del clima religioso en el cual vivió y desarrolló su vida espiritual, sin nombrarlas, Teresa alude a otras mujeres acusadas o condenadas por considerarse alumbradas: "como en estos tiempos habían acaecido grandes ilusiones en mujeres y engaños que las había hecho el demonio, comencé a temer...” (Libro 23.2). Más allá de los eventos de la década de 1520, el proceso inquisitorial de Magdalena de la Cruz de la década de 1540 estaría presente tanto en la memoria de Teresa como en la de sus lectores. Y en la década de 1550 el proceso contra el arzobispo de Toledo fray Bartolomé Carranza de Miranda, ${ }^{18}$ y los autos de fe donde habían sido condenados religiosos y religiosas mantendrían a flor de piel el peligro de ser acusado de alumbrado.

La suerte de mujeres como Magdalena de la Cruz impactó la vida y el texto de Teresa. Aunque Magdalena no escribió sus experiencias, según Alison Weber, su influencia fue necesariamente pertinente: "Teresa lived, inevitably, under the shadow of Magdalena de la Cruz". ${ }^{19}$ Magdalena era una monja que había llegado a ser abadesa en su convento, Santa Isabel Francisca, en Córdoba. Se decía que Magdalena recibía mercedes espirituales y se la veneraba en círculos aristocráticos (Ahlgren 1996: 21-22; Weber, 1990: 4-5, n.5). ${ }^{20}$ Se la acusó de hacer un pacto con el demonio: "tenía familiar dende que fue de cinco años y cuando le via de esta edad pensaba que era angel hasta que de doce años que confesó ser demonio y hizo pacto y conveniencia con él y él prometió de sustentarla por gran tiempo en grandes onrras” (Imirizaldu, 1977a: 47). ${ }^{21}$ Se sentenció públicamente a Magdalena en Córdoba (1546). La sentencia detallaba su castigo mandando "que esté encerrada perpetuamente en un monasterio de la orden de Santo Francisco" (Imirizaldu, 1977b: 61), donde había de ser la persona más baja que necesitaba permiso para hablar y para comulgar, y a quien ya no se le permitía llevar el velo (Imirizaldu, "Sentencia” 1975b: 61-62). No está claro por qué cayó en desgracia Magdalena de la Cruz, pero fue juzgada por pactar con el demonio después de décadas de experiencias sobrenaturales, que sólo confesó “como

\footnotetext{
${ }^{18}$ Carranza, entre otras cosas, había asistido a la primera y a la segunda convocatoria del Concilio de Trento; había sido provincial de Castilla; había trabajado en Inglaterra "por la restauración del catolicismo' (Jericó Bermejo, 150) y había sido nombrado arzobispo de Toledo en 1558. Su proceso hace notar que nadie estaba fuera del alcance de la represión llevada a cabo por el Santo Oficio.

19 “Teresa vivió, inevitablemente, bajo la sombra de Magdalena de la Cruz”) (1990:44).

${ }^{20}$ Pero en la década de 1540, según una carta de otra monja del convento de Magdalena (1544)

${ }^{21}$ La cita proviene de una carta escrita por otra monja del convento de Magdalena, fechada en 1544.
} 


\section{Algunas reacciones de los primeros lectores del Libro de la Vida}

vido que era ya descubierta” (Imirizaldu, 1977a: 45). Según Gillian Ahlgren "[t]he downfall of Magdalena de la Cruz... was a result of suspicion about women's spiritual experiences and a confirmation for religious hierarchs that women were not reliable spiritual leaders". 22 Por lo tanto, parece que las dificultades de Magdalena fueron causadas por una vida espiritual colorida que se manifestaba externamente y que se percibía como una amenaza, particularmente por ser Magdalena una mujer. Teresa se enfrentó al mismo problema. Ella era la única que podía interpretar sus experiencias sobrenaturales, pero como mujer su interpretación no era confiable.

Un breve examen de libros que tratan sobre la mujer como el Jardín de las nobles doncellas de Fray Martín de Córdoba (1499), el Tratado de las supersticiones y hechicerías de Castañega (1529), y aun La perfecta casada de Fray Luis de León (1583), fácilmente nos recuerda la actitud hacia las mujeres en el siglo XVI. Estos textos revelan que la condición "natural” de la mujer era una de debilidad física, condición que causaba a su vez debilidad moral y espiritual, que determinaba que la mujer había nacido para ser humilde y estar sujeta a los hombres. ${ }^{23}$ Además, esta tradición misógina no exigía que se educara a las mujeres, ni mucho menos esperaba que escribiesen ni enseñasen cosas de doctrina. Un pasaje de La perfecta casada resume las "limitaciones" de la mujer con respecto al estudio: "así como la naturaleza [...] hizo a las mujeres para que encerradas guardasen la casa, así las obligó a que cerrasen la boca. [...] [A] la mujer buena y honesta la naturaleza no la hizo para el estudio de las ciencias ni para los negocios de dificultades, [...] así les limitó el entender, y por consiguiente, les tasó las palabras y las razones” (1987: 154). Entonces, Teresa, como mujer se encontraba doblemente necesitada de protección, su persona y su Libro ensombrecidos por el alumbradismo y las experiencias y la condena de Magdalena de la Cruz.

\footnotetext{
22 "la caída de Magdalena de la Cruz... se debió al recelo acerca de las experiencias espirituales de mujeres y a la confirmación para los jerarcas religiosos de que las mujeres no eran líderes espirituales fiables" (21).

${ }^{23}$ Sirva de ejemplo un pasaje del Tratado de Castañega: "Destos ministros al demonio consagrados y dedicados hay más mujeres que hombres. Lo primero, porque Cristo las apartó de la administración de sus sacramentos, por esto el demonio les da esa autoridad más a ellas que a ellos en la administración de sus execramentos. Lo segundo, porque más ligeramente son engañadas del demonio... Lo tercero, porque son más curiosas en saber y escudriñar las cosas ocultas, y desean ser singulares en el saber, como su naturaleza se lo niegue. Lo cuarto, porque son más parleras que los hombres, y no guardan tanto secreto... Lo quinto, porque son más sujetas a ira, y más vengativas...” (63-64).
} 


\section{Raquel Trillia}

\section{LAS TACHAS}

Dos ejemplos servirán para ilustrar cómo pocas palabras podían añadir asociaciones y contenido no deseados por la Iglesia. En el capítulo 17 del Libro, hablando del tercer grado de oración, Teresa escribe: "En fin es que las virtudes quedan ahora más fuertes que en la oración de quietud pasada; que el alma no las puede inorar porque se ve otra y no sabe cómo" (Libro 17.3). La frase tachada -según Tomás Álvarez, (1999b, 2:142) por un "revisor tardío, por purismo teológico- - es “que el alma no las puede ynorar," frase que le da al texto un tono alumbradista porque comunica el hecho de que el alma no tiene control sobre lo que siente en estado de oración avanzada. En la edición príncipe, Fray Luis transcribe lo tachado. Llamas et al., en su edición de 1976 no transcriben lo tachado. Su nota al pie de página reza de la siguiente manera

A continuación aparece en el autógrafo una línea tachada, de letra de la Santa, que parece decir: "que el alma oiga sin que más dé ni haga". Parece que el P. Báñez quiso modificar la frase, tachando algunas palabras, e introduciendo el verbo 'ignorar'. No quedó satisfecho del arreglo, y lo tachó todo, poniendo al margen un reclamo: 'el alma', sin correspondencia en el texto (124).

Primero, debe notarse el uso repetido de la palabra parece que señala que todo lo dicho es especulación. Además, cualquiera de las transcripciones que se acepten apunta al alumbradismo: "[Q]ue el alma oiga sin que más dé ni haga" se inscribe en el abandonarse a Dios que distingue el dejamiento de los alumbrados.

Algo similar ocurre en un párrafo del capítulo 20, donde se lee: “Tengo para mí que un alma que allega a este estado, que ya ella no habla ni hace cosa por sí, sino que de todo lo que ha de hacer tiene cuidado este soberano rey" (Libro 20.24). La frase tachada es "que ya ella no habla ni açe cosa por si [syno]" que sugiere que el alma, en este estado de oración, no puede actuar por sí misma, que queda toda dispuesta a la voluntad de Dios. Siendo este el caso, el individuo deja de ser responsable de sí mismo, idea que también puede haberse interpretado como demasiado parecida a la filosofía de los alumbrados y a su práctica del "abandono completo a Dios" (Bataillon 1966: 169). Esta abdicación de la voluntad humana a la de Dios suponía una "falta de responsabilidad moral, pues el dexado no podía pecar mortal ni venialmente, una vez que sus determinaciones nada tenían de voluntarias y procedían de Dios” (Serrano y Sanz 1903: 10). Esta correlación —el no poder pecar en estado de oración avanzada - iba en contra del formalismo religioso (Bataillon 1966: 173; Ahlgren 1966: 14) y era considerada una 
Algunas reacciones de los primeros lectores del Libro de la Vida

herejía por la Inquisición (Weber, 1990: 24), y tanto Teresa como sus confesores querían diferenciar su espiritualidad de los movimientos heterodoxos que habían sido condenados por la Iglesia a partir de la década de 1520, lo cual explica las tachas señaladas.

Algunos editores de la obra de Teresa (Álvarez y Chicharro, 1999) atribuyen las tachaduras que tocan sobre doctrina - como las ya mencionadas - a lo que llaman un "escrúpulo teológico" por parte del censor, que casi siempre especulan que es Báñez. Esto parece un eufemismo para glosar el hecho de que estas palabras indican que la espiritualidad de Teresa estaba influenciada por corrientes espirituales de su siglo, específicamente alumbradismo y dejamiento, ${ }^{24}$ que habían caído bajo la censura inquisitorial a partir de 1525. Pareciera que la doctrina que presenta Teresa todavía se viera necesitada de protección. Esto es aún más notable si se tiene en cuenta que ya Fray Luis en 1588, como primer editor de la obra de Teresa, incluye en su edición muchas de las frases tachadas por los censores, incluidas las dos que mencioné, probablemente pensaría que el peligro era mínimo, pues, Teresa había muerto en 1582.

Otro grupo de tachas, también pequeño en número, refleja el deseo de minimizar la autoridad de la voz autora. Por ejemplo, en el Capítulo 17.4 del Libro "digo que se ve claro" está borrado, tacha que Silverio de Santa Teresa (130), Efrén de la Madre de Dios (80) y Chicharro atribuyen a Báñez, y que Chicharro explica como "prejuicio teológico" (242). Pero si tenemos en cuenta que la frase sigue la afirmación de que en este estado de oración "la voluntad está atada y gozando,” se justifica especular que es la falta de libre albedrío que preocuparía a la Iglesia y como consecuencia no deseaba que se presentase esta posibilidad con tanta fuerza y confianza. Aquí la tacha modifica el tono y no el contenido del párrafo. Es de notar que Fray Luis, en la edición príncipe, también siente que es necesario modificar el texto. Suple “conócese” (Álvarez, 1995:142). De manera similar, en el epígrafe del Capítulo 18 fueron tachadas las palabras "por esçelente manera” y "lease con advertençia porque se declara por muy delicado modo y tiene cosas mucho de notar." Silverio de Santa Teresa atribuye estas tachaduras a Báñez "tal vez por el elogio que de la doctrina de este capítulo encierran” (134, n. 1). Chicharro también le adjudica la tacha a Báñez y sugiere que "este título [le]

${ }^{24}$ En la Relación 3, después de haber usado el vocablo recogimiento, Teresa escribe "Guárdame tanto Dios en no ofenderle, que cierto algunas veces que me espanto; que me parece veo el gran cuidado que trae de mí, sin poner yo en ello casi nada, siendo un piélago de pecados y maldades antes de estas cosas, y sin parecerme era señora de mí para dejarlas de hacer. Y para lo que yo querría se supiesen, es para que se entienda el gran poder de Dios” (3.12, el subrayado es mío). En este pasaje Teresa sugiere una sumisión a la voluntad de Dios a la manera de los dejados. 


\section{Raquel Trillia}

debió parecer excesivamente presuntuoso” (1993: 246, n.2). En todo caso, estas tachas reducen el matiz de autoridad del epígrafe y por lo tanto del contenido del capítulo que describe. Con el mismo objetivo en el epígrafe del Capítulo 20 está tachado por otra mano "es de mucha admiración.” La necesidad de atenuar la autoridad de la voz teresiana se desprende particularmente del hecho de que era Teresa una mujer y de las "limitaciones" (ya señaladas) que se entendía tenía la mujer en el siglo XVI.

\section{LAS MODIFICACIONES}

Los cambios hechos al autógrafo son pocos. Pueden dividirse en dos grupos: cambios que modifican el significado del texto y cambios de poca trascendencia. El primer grupo encuentra sus causas en el contenido del pasaje o en el tono del mismo. El segundo grupo de modificaciones menores indica el cuidado con que fue leído el autógrafo e incluye correcciones ortográficas y gramaticales (por ejemplo, concordancia de género o número, adición o tacha de pronombres de objeto directo e indirecto, o corrección de los mismos).

$\mathrm{Al}$ primer grupo corresponde el cambio del verbo "vea” por "crea” en un pasaje en el cual, hablando de oración avanzada, Teresa explica que en el tercer grado el alma "comienza a obrar grandes cosas con el olor que dan de sí las flores, que quiere el Señor que se abran para que ella vea que tiene virtudes, aunque ve muy bien que no las podía ella, ni ha podido ganar en muchos años, y que en aquello poquito el celestial hortelano se las dio" (Libro 17.3). La sustitución de "creer" minimiza la fuerza de la aseveración de Teresa; cambia la presentación de algo que la escritora estima objetivo, es decir, que el alma entiende tener virtudes, en algo subjetivo, o sea, que solamente ella, su alma, juzga que tiene virtudes. Este cambio suaviza el tono de autoridad del párrafo.

Un poco más adelante, Teresa explica que como consecuencia de un arrobamiento, entre otras cosas, una persona "ya no quiere querer, ni querer libre alvedrío no querría, y ansí lo suplica al Señor; dale las llaves de su voluntad” (Libro 20.22). En el autógrafo, "libre alvedrío no querría” está borrado por otra mano que sobreescribe "otra voluntad sino hazer la de nuestro señor.” Este cambio es significativo. Teresa dice que el alma ya no desea tener libre albedrío. Pero según el reemplazo del censor el alma solamente desea hacer la voluntad de Dios, es decir, que elige hacer la voluntad de Dios, así ejerciendo su libre albedrío. Dada la controversia sobre 


\section{Algunas reacciones de los primeros lectores del Libro de la Vida}

el libre albedrío ${ }^{25}$ que suscitaron los movimientos reformadores del siglo XVI, y la negación de su existencia por parte de Lutero y Calvino, ${ }^{26}$ el censor consideró importante tachar la idea de que el hombre pueda encontrarse en un estado en el que no pueda ejercer su voluntad. ${ }^{27}$ Fray Luis en su edición, por el mismo motivo, acepta la corrección de censor (Álvarez, 1999b: 551).

El siguiente cambio pertenece al segundo grupo, es decir, al grupo que no cambia apreciablemente el texto. Hacia el final del Libro, contando las profecías que le ha hecho Dios, Teresa describe una de la siguiente manera: "Habiéndose muerto un cuñado mío súpitamente, y estando yo con mucha pena por no se haber vyado a confesarse, se me dijo en la oración que había ansí de morir mi hermana...” (34.19). Las palabras "vyado a” están tachadas con una sola línea, de modo que pueden leerse claramente, y corregidas de otra mano que sobreescribe "por no aver tenido lugar [de]”. Según Cejador y Frauca uviar (sin ' $h$ ') quiere decir en castellano medieval "llegar al encuentro, acontecer” o "tener ocasión o lugar” y huviar (con 'h') significa "hallar medio de, poder". Esto permite pensar que la palabra "vyado" de Teresa es un error tipográfico donde el cambio del censor no altera el significado, sino que sustituye una palabra algo arcaica por una frase más corriente. Esto

\footnotetext{
${ }^{25}$ Que Caro Baroja llama el “mayor tema” de los siglos XVI y XVII (239), para expresar la importancia de esta noción que se oponía a la idea de la predestinación.

${ }^{26}$ Erasmo había defendido el libre albedrío en Diatribe seu collatio de Libero Arbitrio (1524), texto al que Lutero respondió con De Servo Arbitrio, donde sostiene que "el libre albedrío es un mito, un nombre que no encubre ninguna realidad, pues no está en el poder del hombre concebir el bien o el mal, ya que los eventos ocurren por necesidad [...] enfatizando la impotencia y esclavitud del hombre. [...] Con Calvino, la preordenación de Dios es [...] aún más fatal al libre albedrío. El hombre no puede realizar ninguna clase de acción buena a menos que sea obligado a ello por la gracia de Dios que le es imposible resistir" (Enciclopedia Católica, en línea visitada). El Concilio de Trento (1545-1563) “[h]abiéndose difundido en estos tiempos, no sin pérdida de muchas almas, y grave detrimento de la unidad de la Iglesia, ciertas doctrinas erróneas sobre la Justificación,” condenó estas ideas afirmando que el libre albedrío del hombre podía cooperar libremente con la gracia de Dios, “de modo que tocando Dios el corazón del hombre por la iluminación del Espíritu Santo, ni el mismo hombre deje de obrar alguna cosa, admitiendo aquella inspiración, pues puede desecharla; ni sin embargo pueda moverse sin la gracia divina a la justificación en la presencia de Dios por sola su libre voluntad”. Cfr. Decretos del Concilio de Trento, Sessión VI, caps. I y V.

${ }^{27}$ En el Libro hay otra instancia en la que Teresa cita el libre albedrío: "No se puede decir lo que en este caso [cuando el demonio interviene con el alma cuando está en estado de oración] se padece. Ella [el alma] anda a buscar reparo y primite Dios no le halle; sólo queda siempre la razón del libre albedrío, no clara” (30.11). Según Chicharro, es esta "expresión de sentido dudoso, que tal vez designe la fuerza de la razón que preside el libre ejercicio de la libertad" (360, n.20). Si la interpretación de Chicharro es correcta, e igual a la interpretación de los primeros lectores del autógrafo, entonces, se explica por qué, en este caso, la mención del albedrío no necesitaba ser tachada. La traducción del Libro de Kavanaugh y Rodríguez [1976] interpreta el pasaje de la misma manera que Chicharro.
} 


\section{Raquel Trillia}

solamente sería necesario de hacer si se pensara que el texto iba a ser leído por otros para quienes el cambio facilitaría la lectura, lo que presupone que al menos uno de sus lectores tempranos veía como deseable la posibilidad de que un público más amplio leyera el Libro.

Un cambio que sugiere el cuidado con que fue leído el autógrafo es el reemplazo de "humilla” por la palabra "humana” en el siguiente pasaje: “[en tiempos de quietud] no hay que argüir, sino que conocer lo que somos con llaneza, y con simpleza representarnos delante de Dios, que quiere se haga el alma boba..., pues su Majestad se humilla tanto, que la sufre cabe sí, siendo nosotros lo que somos” (15.8). Según Chicharro, es Báñez quien inserta la palabra "humana" (229, n.15), que parece una sugerencia más que un cambio ya que no se tacha el vocablo elegido por Teresa. Siendo tan importante la humildad para el cristiano que aspira ser virtuoso, y siendo una virtud de la que Teresa se aprovechó en su modo de escribir, es interesante notar que el censor prefiere la noción de que Dios se "humane,” calificación más amplia que "humilla”. Creando lo que Alison Weber llama una retórica de humildad, Teresa aprovecha la tradición del topos de la modestia para constantemente solicitar la cooperación del lector (Rhetoric 50).

Cabe pensar que atribuir humildad a Dios, según el censor, sería problemático, ya que siendo Él justamente Dios, ¿por qué y ante quién humillarse? Es al Hombre a quien le toca humillarse ante Dios. Sin embargo, en su Tercer abecedario (que Teresa había leído) Francisco de Osuna escribe que la humildad es "a todo necesaria," y es también "la primera entrada en la religión, así como el primer paso de Cristo en el mundo” (498). Si el humanarse de Cristo al hacerse hombre fue humillarse al nacer en un establo y morir en la cruz (Francisco de Osuna, 509), entonces el sentido del pasaje según lo expresó Teresa no queda alterado por el censor y su sugerencia puede atribuirse a una preferencia de expresión. Sin embargo, según Álvarez, la sustitución del censor es a causa de "remilgos de ortodoxia" que no elabora (Nota 552).

Otro cambio de vocablo que no altera apreciablemente el texto ocurre en el epígrafe del Capítulo 17, que trata sobre el tercer grado de oración, que se lee de la siguiente manera: "Prosigue de la mesma materia de declarar este tercer grado de oración; acaba de declarar los efectos que hace; dice el daño que hace aquí la imaginación y memoria.” Otra mano reemplazó la palabra “daño” por “ympidimiento.” Según Covarrubias (1943), daño quiere decir el "menoscabo que uno recibe en su persona, hazienda, honra y todo lo que le puede pertenecer," e ympidimiento significa "estorvo, obstáculo, tropieço." Daño, por lo tanto, en el contexto del epígrafe se refiere a los efectos o consecuencias negativos de la acción de la memoria y de la imaginación sobre el alma en un estado avanzado de oración, mientras ympidimiento significa 


\section{Algunas reacciones de los primeros lectores del Libro de la Vida}

“obstáculo”, es decir, algo que inhibe la acción de la memoria y de la imaginación, cambiando su papel en el epígrafe y por lo tanto en la oración espiritual. Pero, en este Capítulo, Teresa explica que en la oración de quietud "la memoria queda libre y junto con la imaginación debe ser; y ella, como se ve sola, es para alabar a Dios la guerra que da y cómo procura desasosegarlo todo. A mí cansada me tiene y aborrecida la tengo... [...] como faltan las otras potencias, no valen [la memoria y la imaginación], aun para hacer mal, nada. [...] porque no tienen fuerza...” (Libro 17.5-6). Teresa concluye que aunque la memoria y la imaginación la estorban en oración de quietud, no pueden hacerle daño. Puede entonces conjeturarse que el censor, habiendo leído el capítulo, vuelve al epígrafe para corregirlo según esta interpretación del texto. El cambio, entonces, altera el significado del epígrafe, pero para acordarlo con el contenido del capítulo que anticipa. Quizás por esta razón algunos editores modernos, como Efrén y Otger Steggink, conservan la enmienda (Chicharro, 240, n.1). Fray Luis respetó el texto teresiano, lo mismo que muchos editores modernos como Silverio de Santa Teresa y Llamas et al., simplemente señalando el cambio en nota al pie de la página.

Los cambios hechos al manuscrito por otra mano sugieren que los censores no encontraron graves problemas doctrinales con su contenido, aunque debe tenerse en cuenta que si el manuscrito no estaba en circulación, su contenido ya no necesitaba considerarse peligroso. Dicho esto, es de notar que los cambios, aunque no sean sustanciales, se encuentran en las secciones del texto que tratan sobre arrobamiento y sobre profecía, ambas experiencias espirituales problemáticas por su misma naturaleza. El lector/censor se veía ante la necesidad de creerle a Teresa o no, sin poder verificar lo escrito, lo cual puede explicar que el censor leyera con más detenimiento estas secciones del texto.

Otro aspecto del texto que debe tenerse en cuenta al observar el cuidado con el que fue tratado el manuscrito y los pocos cambios hechos en éste por otra mano de es que, como demuestra Weber, el Libro, a lo largo de varios años (1554-1565) tuvo varias versiones, sufriendo correcciones y expansiones de las que participaron sus confesores: "there are indications that very early on in the process of composition of the Vida, the relationship between Teresa and the 'spiritual men' was no longer adversarial, and that their shared concern was that she express herself with the correct terminology and avoid anything that could be misinterpreted as alumbrado error". ${ }^{28}$ Es decir, que el

\footnotetext{
28 "hay indicios de que durante el proceso de composición del Libro, muy pronto la relación entre Teresa y los 'hombres espirituales' no fue una de confrontación, y que su preocupación compartida era que ella se expresara con la terminología correcta y que evitara cualquier cosa que pudiese ser malinterpretada como error alumbrado” (2003: 109).
} 


\section{Raquel Trillia}

texto frente al cual nos encontramos nosotros no es ni un primer borrador, ni el producto de Teresa escribiendo a solas; es el producto de muchos años de escritura, reflexión y diálogo. De hecho, la misma Teresa, en su Relación 54 en la cual hace relación de su vida espiritual, cuenta cómo procuraba tratar con personas espirituales y letrados "porque ella no quería saber sino si [su oración] era conforme a la Sagrada Escritura todo lo que tenía” (54.9). En esta Relación nombra una serie de confesores y letrados con quienes trató y se confesó a lo largo de muchos años, escribe en 1576. Y su primer biógrafo, Francisco de Ribera, quien la había conocido, entre otras cosas, quiere establecer esta dependencia del aviso y consejo de confesores y letrados por parte de Teresa, entre otros, “[c]on este Padre [Francisco de Borja] se consoló ella mucho, porque le preguntó muchas cosas y, como hombre de mucha experiencia en ellas, la satisfizo" (135). Ribera también dedica un capítulo a la relación espiritual entre Teresa y Pedro de Alcántara. Teresa le dio "cuenta de sí misma a este santo varón. Y aunque ella entonces no sabía declararse en estas cosas tan espirituales, él, como era de grandísima penitencia y oración, luego la entendía, y dióla mucha luz, y aseguróla mucho” (151). Ribera presenta a una Teresa guiada por hombres que sabían más de oración que ella. Teresa no sabía expresarse; hombres como Francisco de Borja, Francisco de Ribera, Baltasar Álvarez y Francisco de Salcedo (por nombrar algunos) la ayudaron no sólo a interpretar el origen de sus experiencias y a desarrollar su modo de oración, sino que le suministraron el vocabulario y modo de expresarse adecuados a sus experiencias y a la ortodoxia del momento.

\section{LAS ADICIONES}

La tercera y última categoría de modificaciones al texto que trataré en este trabajo son las adiciones. Algunas de éstas intentan suplir los lapsi de Teresa. Por ejemplo, en el Capítulo 8, al defender la oración, Teresa escribe: "[...] y quisiera tener licencia para decir las muchas veces que en este tiempo falté a Dios por estar arrimada a esta fuerte coluna de la oración” (Libro 8.1).

Un censor agregó "no" delante de "estar arrimada”. Según Dámaso Chicharro, como en este contexto "por" puede equivaler a "para," el pasaje "tendría sentido" $(169$, n.1) como lo escribió Teresa. Según esta lectura el pasaje explicaría que la vida ruin de Teresa se debe a su deseo de intimidad con Dios, lectura que no sigue Chicharro, pero que se ajusta a un aspecto de la retórica teresiana a través de la cual sus actos de confesión se encuentran de la mano de elementos defensivos, lo que Weber denomina una retórica de concesión (1990: 52). Sin embargo, distintos editores del texto no se han puesto de acuerdo en cuanto la lectura de este pasaje, ya que Fray Luis, Lafuente y Silverio incluyen el "no" como Chicharro, en tanto que Heitz y 


\section{Algunas reacciones de los primeros lectores del Libro de la Vida}

Efrén omiten el "no” (Álvarez 1995: 263). Llamas et al. Conservan el "no”, lo mismo que Kavanaugh y Rodríguez en su traducción del Libro. Además, la interpolación del "no" permite una doble lectura según se puntúe la oración después de "a Dios" o después de "la oración”. Agregado el "no" y puesto el punto después de "oración” el pasaje lee "[...] y quisiera tener licencia para decir las muchas veces que en este tiempo falté a Dios por [no] estar arrimada a esta fuerte coluna de la oración”. Esta lectura sugiere que el censor, y luego varios editores, creen que Teresa olvidó escribir el "no" que cambia el significado del texto considerablemente, explicando que su ruin vida se debe a su falta de oración, lectura también posible, ya que Teresa deseaba justificar el beneficio de sus modos de oración. Ahora, si se puntúa la oración después de "a Dios” leemos: “[...] y quisiera tener licencia para decir las muchas veces que en este tiempo falté a Dios. Por [no] estar arrimada a esta fuerte coluna de la oración pasé este mar tempestuoso casi veinte años...” que ahora explica que por no estar con oración, pasó veinte años sufriendo "una guerra tan penosa" entre el placer que le daban las cosas del mundo y el placer que le daba estar con Dios (Libro 8.1-2). Esta lectura parece imposible ya que Teresa se contradiría en la misma oración, en la cual diría estar a la misma vez con y sin oración. Debemos concordar con los editores de Teresa que asumen que la ausencia del 'no' es un lapsus del texto. ${ }^{29}$

Las adiciones al texto algunas veces suplen las legítimas faltas por equivocación que contiene el texto. Por ejemplo, en el capítulo 20 del Libro, Teresa escribe "[d]igo, "no sabe”, porque no representa nada la imaginación; ni, a mi parecer, mucho tiempo de lo que está ansí obran las potencias: como en la unión y arrobamiento el gozo, así aquí la pena las suspende” (20.11). Otra mano agrega un "no" quedando "[no] obran las potencias," para concordar con el final de la oración, que explica que quedan suspendidas, es decir, paradas, perplejas (Covarrubias, 1943) o interrumpidas. Esta adición complementa otras correcciones que simplemente corrigen lapsi menores de la escritora, por ejemplo, en el Capítulo 8 en el margen derecho del reverso del folio xxxiii un lector agregó la silaba 'ra' para completar la palabra "procu[ra]". Lo mismo ocurre en el margen derecho del folio siguiente (xxxiiii) en la ultima línea (28) donde se agrega 'ra' para completar "mane[ra]".

\footnotetext{
${ }^{29}$ Otro caso similar, aunque de significación estilística, es el añadido de la preposición "con” al final de una línea dando "es como uno que está [con] la candela en la mano" (Libro 16.1). No es necesario el "con," aunque muchos editores lo han agregado a partir de Fray Luis. Según Chicharro "son muy abundantes en Santa Teresa estas construcciones sintéticas, que prescinden de elementos de enlace” (234, n.5). La adición es, por lo tanto, un retoque estilístico. Editores modernos insertan una coma para suplir la falta de la preposición.
} 


\section{Raquel Trillia}

La última categoría de las adiciones corresponde a las que suavizan la autoridad de texto teresiano. Por ejemplo, en un pasaje que lee "Digo que para rendirse un alma del todo a estar sujeta a solo un maestro, que yerra mucho en no procurar que sea tal [letrado], si es relisioso, pues ha de estar sujeto a su perlado..." (Libro 13.19), otra mano agrega la preposición "de" cambiando "a estar sujeta” a "a de estar sujeta." Teresa aquí trata las cualidades deseables en un maestro espiritual, en particular el valor de las letras en los que "no tienen espíritu" (Libro 13.18). El pasaje explica que el alma necesita permitirse estar sujeta a un solo maestro que sea letrado, mientras que la adición de la preposición “de” agrega la necesidad de estar sujeta el alma a un solo maestro espiritual. Esta adición quizás refleje la conciencia por parte del lector de la aventura espiritual de Teresa que incluyó varios maestros espirituales y la queja de vivir muchos años sin uno que la comprendiese y guiase bien (Libro 22.3 y 30.6). A su vez, la adición transforma lo que Teresa considera deseable en algo indispensable, ya que la sombra del alumbradismo exige que se presente como necesaria la intervención de un maestro en el progreso espiritual del alma.

En otro pasaje, en el que trata el tema del tercer grado de oración, Teresa explica que "[el alma] ve claro que no hacían nada los mártires de su parte en pasar tormentos; porque conoce bien el alma viene de otra parte la fortaleza” (Libro 16.4). La palabra "casi” está sobreescrita por una mano ajena quedando "no açian [casi] nada," adición que suaviza la afirmación, sobre todo estando, ésta, prologada de la certidumbre de que el alma "ve claro”. Álvarez sugiere que el añadido supone un "escrúpulo teológico” del censor, frase que supone que el censor pensaba, o temía, que lo escrito no se ajustara estrictamente a la doctrina de la Iglesia. Es posible que el que los mártires "no hacían nada de su parte" tenga demasiado sabor protestante, insinuando la ausencia de libre albedrío. ${ }^{30}$ Las adiciones al texto, entonces, cumplen varias funciones: corrigen errores tipográficos, eliminan temas peligrosos y suavizan la autoridad del texto.

\footnotetext{
${ }^{30}$ Este añadido es de interés particular porque el texto teresiano se encuentra plagado de frases semejantes, como "vese claro", "he visto claro", "entiende claro", "ve más claro", etc., que no fueron ni tachadas ni suavizadas. Las 14 instancias de la frase "ve claro" indican el uso frecuente de esta frase o equivalentes para expresar certeza y comprensión de lo que dice. Estas frases forman parte de uno de los discursos de Teresa, "el de la autoridad, del atrevimiento, un discurso pedagógico, casi sermonario, de una persona que goza una unión con Dios". Fernández contrasta estas frases con el discurso "de la sumisión, del silencio confesional, de una persona que se somete al juicio definitivo de sus lectores autoritarios" (287). Además, si entendemos el Libro de Teresa como una 'colaboración' entre ella y sus confesores, puede leerse la ausencia de más tachas de este tipo de afirmaciones como muestras de apoyo a su forma de oración y a su persona que ya habían sido censuradas.
} 
Algunas reacciones de los primeros lectores del Libro de la Vida

En síntesis, este estudio de las marcas del autógrafo del Libro de la vida permite llegar a la conclusión de que fue leído con detenimiento y que era importante censurar su doctrina más que su estilo. Había que evitar asociaciones o connotaciones alumbradistas, que de hecho algunos vieron en el modo de oración de Teresa. Llamas Martínez resume las acusaciones que se hicieron contra Teresa y sus libros de la siguiente manera: "que enseñaba cosas de Alumbrados, que practicaba una oración mental, que ponía como estilo de vida en sus conventos, y que era idéntica a la de los alumbrados de Llerena; que la doctrina de sus libros era la misma que profesaban los adictos a la secta de los alumbrados en Extremadura y Andalucía” (“Alumbrados” 137). En este contexto el Libro fue leído y re-leído para evaluar las secciones en las cuales Teresa explica su modo de oración, cuando expresa ideas o narra experiencias subjetivas, y cuando se expresa con certidumbre o autoridad. A su vez, el cuidado con que fueron hechas estas correcciones, las muchas marcas que señalan líneas o párrafos, y las tachaduras que eliminan asociaciones alumbradistas sugieren que estos lectores buscaban proteger a Teresa, su doctrina y su manuscrito. Este cuidado también realza que el Libro fue un trabajo de colaboración que Teresa ciertamente confiesa cuando recomienda que al comenzar a tener oración se busque un maestro con experiencia de oración y si es letrado, mejor: "Yo he tratado hartos [letrados] [...] y siempre fui amiga de ellos [...]; porque en la Sagrada Escritura, que tratan, siempre hallan la verdad de buen espíritu” (Libro 13.18). Teresa documenta su consulta con hombres de letras que la han guiado en su trayectoria haciendo que lo que escribió se apreciara, sin ella decirlo, como el resultado de muchas conversaciones con confesores y letrados. En 1591, el Padre Báñez confirmó esto en los Procesos cuando declaró que "siempre se informó de los hombres más letrados que ella hallaba [... y] que se le sosegaba más el espíritu cuando consultaba algún gran letrado” (I.7). Además, el Libro, "tal como actualmente lo conocemos, estuvo precedid[o] de varias redacciones parciales, más o menos amplias, que sirvieron sin duda como primeros materiales para su elaboración” (Llamas Martínez, 1972:229). La conversación con confesores y letrados a lo largo de muchos años y las varias versiones del Libro que Teresa escribiera hicieron que el autógrafo que a nosotros ha llegado sea el resultado de una vida de oración compartida y perfeccionada a partir de consultas con sus "superiores" en materia de doctrina. Podemos considerar que el autógrafo que se encuentra en El Escorial es la versión final o definitiva de su vida y modo de oración, ya censurada por oficiales de la Iglesia (sin ignorar que el texto se vio necesitado de protección aún después de la muerte de Teresa). En lugar de censores, en esta instancia, los lectores actuaron como editores del Libro. 
Raquel Trillia

\author{
University of Lethbridge* \\ 4401 University Drive Lethbridge \\ Alberta (Canadá) T1K 3M4 \\ raquel.trillia@uleth.ca
}

\title{
BIBLIOGRAFÍA
}

AHLGREN, Gillian T.W. Teresa of Avila and the Politics of Sanctity. Ithaca: Cornell University Press, 1996.

ÁLVAREZ, Tomás, ed. Libro de la vida. Autógrafo de la Biblioteca del Real Monasterio de El Escorial. Presentación y transcripción paleográfica. 2 vols. Burgos: Monte Carmelo, 1999a.

Nota histórica. Anexo al vol. II del Libro de la vida. Burgos: Monte Carmelo, 1999b.

ANDRÉS, Melquíades. “Alumbrados, Erasmians, 'Lutherans,' and Mystics: The Risk of a More 'intimate' Sprituality”. The Spanish Inquisition and the Inquisitorial Mind. Trans. Esther da Costa-Frankel. Ed. Angel Alcalá. Boulder, Colorado: Social Science Monographs, 1987. 457494.

BÁÑEZ, Domingo. "Censura del P. Domingo Báñez en el autógrafo de la "Vida”. Obras completas. Teresa de Ávila, Santa 1515-1582. 2a Edición. Madrid: Biblioteca de Autores Cristianos, 1967. 190-91.

------- "Proceso de Salamanca. Dicho del P. Báñez, O. P.”. Procesos de canonización y beatificación de Santa Teresa de Jesús (1591-1610). Ed. Silverio de Santa Teresa. Burgos, 1934-35. vol I. 6-11.

BATAILLON, Marcel. Erasmo y España. Trans. Antonio Alatorre. 2a Edición. México: Fondo de Cultura Económica, 1966.

CARO BAROJA, Julio. Las formas complejas de la vida religiosa (Siglos XVI y XVII). Madrid: Sarpe, 1985.

CASTAÑEGA, Fray Martín de. Tratado de las supersticiones y hechicerías. Ed. Fabián Alejandro Campagne. Buenos Aires: Universidad de Buenos Aires, Facultad de Filosofía y Letras, 1997.

CEJADOR Y FRAUCA, Julio. Vocabulario Medieval Castellano. Alemania: Georg Olms Verlag, 1971.

CHICHARRO, Dámaso. (ed). Santa Teresa de Jesús. Libro de la vida. Madrid: Cátedra, 1993.

COVARRUBIAS, Sebastián de. Tesoro de la lengua española o castellana. Ed. Martín de Riquer. Barcelona: Horta, 1943.

CONCILIO de Trento. Decretos del Concilio de Trento. 1545-1563. Biblioteca electrónica cristiana. 8 de agosto 2007. http://www.multimedios.org/docs2/d000436/p000001.htm 
Algunas reacciones de los primeros lectores del Libro de la Vida

DE LA FUENTE, Vicente. (ed). Escritos de Santa Teresa I y II. Madrid: Biblioteca de Autores Españoles, 1877.

EFRÉN DE LA MADRE DE DIOS Y OTGER STEGGINK. (eds). Obras completas de Santa Teresa de Jesús. Madrid: Biblioteca de Autores Cristianos, 1967.

ENCICLOPEDIA CATÓLICA. Edición digital en línea, ACI-PRENSA. The Catholic Encyclopedia, Volumen I, 1907 por la Robert Appleton Company. Edición en línea 1999 por Kevin Knight. 8 de agosto 2007. http://www.enciclopediacatolica.com///librevoluntad.htm\#IIE

FERNÁNDEZ, James. "La Vida de Teresa de Jesús y la salvación del discurso". MLN 105.2 (1990): 283-302.

OSUNA, Francisco de. Tercer Abecedario Espiritual. Místicos Franciscanos Españoles II. Ed. Saturnino López Santidrián. Madrid: Biblioteca de Autores Cristianos, 1998.

IMIRIZALDU, Jesúsa “Carta dando relación sobre Magdalena de la Cruz”. Monjas y Beatas embaucadoras. Madrid: Editora Nacional, 1977a. 41-50.

------- "Sentencia de Magdalena de la Cruz”. Monjas y Beatas embaucadoras. Madrid: Editora Nacional, 1977b. 51-62.

JERICÓ BERMEJO, Ignacio. "Bartolomé de Carranza (s. XVI). Conocimiento, enseñanza y confesión de la fe católica”. Communio 36.1 (2003) 149-85.

------ El libro del conorte. El Escorial MS J-II-18.

LLAMAS, Enrique; Teófanes Egido et al. (eds). Santa Teresa de Jesús. Obras completas. Madrid: Editorial de Espiritualidad, 1976.

LLAMAS MARTÍNEZ, Enrique. "Teresa de Jesús y los alumbrados. Hacia una revisión del 'alumbradismo' español del siglo XVI”. Actas del Congreso Internacional Teresiano. 2 vols. Salamanca: Universidad de Salamanca-Universidad Pontificia de Salamanca-Ministerio de Cultura, 1982. I, 137-68.

------- Santa Teresa de Jesús y la Inquisición española. Madrid: CSIC, 1972.

LONGHURST, John E. "La Beata Isabel de la Cruz ante la Inquisición”. Cuadernos de Historia de España XXV-XXVI (1957): 279-303.

LÓPEZ SANTIDRIÁN, Saturnino. "Introducción”. Místicos Franciscanos Españoles II. Tercer Abecedario Espiritual de Francisco de Osuna. Madrid: Biblioteca de Autores Cristianos, 1998. 1-82.

LUIS DE LEÓN. La perfecta casada. Ed. Mercedes Etreros. Madrid: Taurus, 1987.

“A las Madres Priora Ana de Jesús y religiosas Carmelitas Descalzas del Monasterio de Madrid, el Maestro Fray Luis de León”. Escritos de Santa Teresa. Madrid: Atlas, 1952, 17-22. 


\section{Raquel Trillia}

MÁRQUEZ, Antonio. Los alumbrados. Orígenes y filosofía (1525-1559). Madrid: Taurus, 1980.

MARTÍN DE CÓRDOBA. "Jardín de las nobles doncellas". Prosistas castellanos del siglo XV. 2 vols. Ed. P. Fernando Rubio. Madrid: Biblioteca de Autores Cristianos, 1964, II, 65-117.

NIETO, José C. "The Nonmystical Nature of the Sixteenth-Century Alumbrados of Toledo". The Spanish Inquisition and the Inquisitorial Mind. Ed. Angel Alcalá. Boulder, (Colorado): Social Science Monographs, 1987, 431-456.

SELKE, Angela. "Algunos datos nuevos sobre los primeros alumbrados. El Edicto de 1525 y su relación con el Proceso de Alcaraz”. Bulletin HIspanique LIV.2 (1952): 125-152.

SERRANO Y SANZ, Manuel. "Pedro Ruiz de Alcaraz, iluminado alcarreño del siglo XVI”. Revista de Archivos, Bibliotecas y Museos VII (1903): 1-16, 126-139.

SILVERIO DE SANTA TERESA (ed.). Obras de Santa Teresa de Jesús. Burgos: Monte Carmelo, 1939.

TERESA DE ÁVILA. Libro de la vida. Autógrafo de la Biblioteca del Real Monasterio de El Escorial. Presentación y transcripción paleográfica de Tomás Álvarez. 2 vols. Burgos: Monte Carmelo, 1999.

------- Libro de la vida. (Ed.) Dámaso Chicharro. Madrid: Cátedra, 1993.

------- Obras completas. Ed. Enrique Llamas, Teófanes Egido et al. Madrid: Editorial de Espiritualidad, 1976.

------- Obras completas de Santa Teresa de Jesús. (Ed.) Efrén de la Madre de Dios y Otger Steggink. Madrid: Biblioteca de Autores Cristianos, 1967.

------- Obras de Santa Teresa de Jesús. Ed. Silverio de Santa Teresa. Burgos: Monte Carmelo, 1939.

------- The Collected Works of Saint Teresa of Avila. Trans. Kieran Kavanaugh y Otilio Rodríguez. 3 vols. Washington, D.C.: Institute of Carmelite Studies, 1987.

WEBER, Alison. Teresa of Avila and the Rhetoric of Femininity. Princeton, NJ: Princeton University Press, 1990.

"The Three lives of the Vida: The Uses of Convent Autobiography". Women, Text and Authority. Ed. Marta E. Vicente y Luis R. Corteguera. London: Ashgate, 2003. 107- 125. 